WellBeing International

WBI Studies Repository

$3-24-2010$

\title{
Non-Invasive Genetic Sampling of Faecal Material and Hair from the Grey-Headed Flying-Fox (Pteropus poliocephalus)
}

\author{
Heather J. Baldwin \\ Macquarie University \\ Stephen J. Hoggard \\ Macquarie University \\ Stephanie T. Snoyman \\ Macquarie University \\ Adam J. Snow \\ Macquarie University \\ Culum Brown \\ Macquarie University
}

Follow this and additional works at: https://www.wellbeingintlstudiesrepository.org/acwp_vsm

Part of the Animal Studies Commons, Other Animal Sciences Commons, and the Other Genetics and Genomics Commons

\section{Recommended Citation}

Baldwin, H. J., Hoggard, S. J., Snoyman, S. T., Stow, A. J., \& Brown, C. (2010). Non-invasive genetic sampling of faecal material and hair from the grey-headed flying-fox (Pteropus poliocephalus). Australian Mammalogy, 32(1), 56-61.

This material is brought to you for free and open access by WellBeing International. It has been accepted for inclusion by an authorized administrator of the WBI Studies Repository. For more information, please contact wbisr-info@wellbeingintl.org.

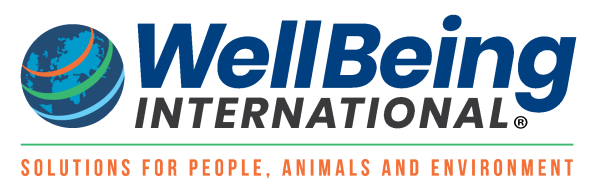




\title{
Non-Invasive Genetic Sampling of Faecal Material and Hair from the Grey-Headed Flying- Fox (Pteropus poliocephalus)
}

Heather J. Baldwin, Stephen J. Hoggard, Stephanie T. Snoyman, Adam J. Stow, and Culum Brown Macquarie University

KEYWORDS

dropout, control region, D-loop, faeces, false alleles, genetic typing, genotyping error, multitube, PCR

\begin{abstract}
Remote-sampling DNA from animals offers obvious benefits for species that are difficult to sample directly and is less disruptive for species of conservation concern. Here we report the results of a pilot study investigating non-invasive DNA sampling of the grey-headed flying-fox (Pteropus poliocephalus), a threatened species that is restricted to the east coast of Australia. We successfully extracted DNA from fresh scats and hair, each of which was of sufficient quality for amplifying mitochondrial DNA markers and microsatellites. A single-locus multitube approach was used to investigate amplification success and genotyping reliability. Faecal samples yielded a higher proportion of successful amplifications and consensus genotype assignments than hair samples. We outline measures that may be utilised to minimise microsatellite genotyping error for future studies. These indirect approaches to obtaining genetic data show much promise given the difficult nature of directly sampling flying-foxes and related species.
\end{abstract}

\section{Introduction}

Non-invasive sampling techniques are becoming more frequently used to sample threatened and elusive animal species (Gerloff et al. 1995; Ernest et al. 2000; Segelbacher and Steinbruck 2001). Remote sampling of DNA via faecal material or hair removes the need for direct interaction with study animals, minimising the risk and stress to the animals involved with blood or tissue collection, and can be particularly useful for studying rare or cryptic species (Sloane et al. 2000; Banks et al. 2002).

Despite initial optimism surrounding the potential of noninvasive techniques, many researchers have called for caution in their application as the quality of the sample obtained is often suboptimal (Gagneux et al. 1997; Taberlet et al. 1999). Faecal-derived samples have relatively low quantities of DNA available for extraction (Piggott et al. 2004) and may be of poor quality due to oxidative damage or enzymatic degradation (Frantzen et al. 1998). Compounding this, substances may be present that increase the incidence of PCR errors, completely inhibit PCR amplification or damage DNA directly (Taberlet et al. 1996; Regnaut et al. 2006; Broquet et al. 2007). As a result, noninvasive samples are often subject to allelic dropout and the inclusion of false alleles (Taberlet et al. 1996; Sloane et al. 2000). 
Collecting genetic data from grey-headed flying-fox (Pteropus poliocephalus) would benefit greatly from remote sampling techniques. A range of threatening processes has seen a dramatic drop in population size (Eby et al. 1999) and consequently the species has been listed as vulnerable under the Commonwealth Environment Protection and Biodiversity Conservation Act 1999 and in NSW and Victoria under the Threatened Species Conservation Act 1995 and the Flora and Fauna Guarantee Act 1988, respectively (Eby and Lunney 2002). P. poliocephalus is endemic to the east coast of Australia and provides important ecosystem services such as long-distance pollination (Eby 1991; Hall and Richards 2000) and seed dispersal (Puddicombe 1981; Eby 1991; Fujita and Tuttle 1991), highlighting the importance of their conservation. Traditionally, sampling involves the use of mist-nets and a hole-punch to sample the wing membrane from which DNA can be extracted (Palmer and Woinarski 1999). This is not only a stressful procedure, but may also injure the animal. Given the current vulnerable status of this species and the difficulty associated with collecting tissue samples, the development of a non-invasive protocol for extracting DNA for this species is favourable. The aim of this study was to develop a method to extract DNA from the faeces of the grey-headed flying-fox in order to amplify microsatellites and mitochondrial loci by Polymerase Chain Reaction (PCR). We tested the reliability of faecal- and hairderived DNA as a potential alternative source of remotely available DNA. We also outline some of the measures that may be utilised to address and minimize microsatellite genotyping error for future studies.

\section{Materials and methods}

\section{Sampling}

Faecal samples were collected between April 2007 and September 2009 from Cabramatta Creek Flying-

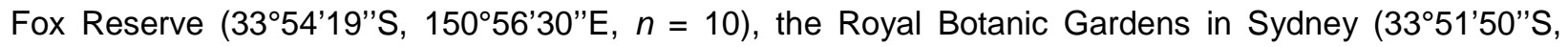

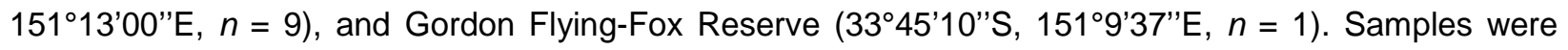
collected by hand using gloves immediately after defecation and frozen at $-20^{\circ} \mathrm{C}$ (Frantzen et al. 1998).

Hair was collected from captive individuals by running a gloved hand through the hair and gently removing shed hairs $(n=7)$. Hair was also plucked directly from one deceased individual, estimated to have died within $24 \mathrm{~h}$ of sampling. Wing tissue samples were kindly donated by Anja Divljan (University of Sydney, Australia) and stored in $70 \%$ ethanol.

\section{DNA extraction}

Extraction of DNA from faecal samples was performed with the use of a QIAamp DNA Stool Mini Kit (Qiagen) according to the manufacturer's instructions for isolation for pathogen detection $(n=17)$, and a Bioline Faecal PCR Kit following the manufacturer's instructions $(n=3)$. Where scats were larger than the size prescribed for the extraction methods, faecal material was removed from the surface of the faecal bolus for extraction. DNA was extracted from hair samples using two methods, the first being a 'saltingout' procedure following Sunnucks and Hales (1996) $(n=4)$ and the second being extraction in a $5 \%$ Chelex suspension following Gagneux et al. (1997), with the following modification: hair was added to the solution without washing in ethanol and water $(n=4)$. Between four and 10 hairs were used per extraction. DNA extraction from wing samples was performed using the 'salting out' procedure.

\section{Mitochondrial DNA PCR amplification}

The D-loop or control region of mitochondrial genome was amplified from faecal $(n=17)$, hair $(n=1)$ and wing $(n=1)$ DNA samples using pre-existing primers (PVDLPL and PVDLPR: Olival 2008). PCRs were performed in a final volume of $10 \mu \mathrm{L}$ containing $0.5 \mathrm{U}$ Taq DNA polymerase (Promega), $10 \mu \mathrm{M}$ forward primer, $10 \mu \mathrm{M}$ reverse primer, $8 \mu \mathrm{M}$ dNTPs, $1 \times$ Taq Buffer (Promega) and $2.0 \mathrm{mM} \mathrm{MgCl}_{2}$. PCR amplifications had an initial denaturation at $94^{\circ} \mathrm{C}$ for 4 min followed by five 'touch down' cycles of $94^{\circ} \mathrm{C}$ 
denaturation for $15 \mathrm{~s}$, annealing temperatures $\left(55^{\circ} \mathrm{C}, 54^{\circ} \mathrm{C}, 53^{\circ} \mathrm{C}, 52^{\circ} \mathrm{C}, 51^{\circ} \mathrm{C}, 50^{\circ} \mathrm{C}\right)$ for $30 \mathrm{~s}$ and an extension step of $72^{\circ} \mathrm{C}$ for $80 \mathrm{~s}$. On the completion of the last touchdown cycle, another 30 cycles were carried out at $50^{\circ} \mathrm{C}$ annealing temperature with a final extension of $5 \mathrm{~min}$ at $72^{\circ} \mathrm{C}$. PCR products were visualised on $2 \%$ agarose gel. Samples that failed to amplify were rerun using a DNA template diluted to one in five, to reduce the likelihood of inhibition, with a PCR program comprising denaturation at $94^{\circ} \mathrm{C}$ for $3 \mathrm{~min}$ followed by 35 cycles of $94^{\circ} \mathrm{C}$ for $30 \mathrm{~s}$, annealing at $50^{\circ} \mathrm{C}$ for $30 \mathrm{~s}$, extension at $72^{\circ} \mathrm{C}$ for 1 min and a final extension step of $72^{\circ} \mathrm{C}$ for $5 \mathrm{~min}$. PCR products were purified using ExoSap-IT (USB) and sequenced using dye terminator sequencing on a $3130 \times 1$ Genetic Analyser (Applied Biosystems). Sequences were then compared on GenBank using the blast(n) function to ensure that the amplified product originated from grey-headed flying-fox.

\section{Nuclear DNA PCR amplification}

DNA extracted from faecal, hair and wing samples were amplified using eight pre-existing microsatellite primers developed for Pteropus spp. (Fox et al. 2007; O'Brien et al. 2007) (Table 1). For the purpose of genotyping, forward primers were labelled with fluorochrome at the 50 end. PCRs were performed with a final volume of $10 \mu \mathrm{L}$ containing $0.5 \mathrm{U}$ Taq DNA polymerase (Promega), $10 \mu \mathrm{M}$ forward primer, $10 \mu \mathrm{M}$ reverse primer, 0.5\% BSA, $8 \mu \mathrm{M}$ dNTPs, 1 x Taq Buffer (Promega) and $2.0 \mathrm{mM} \mathrm{MgCl}$.PCRamplifications had an initial denaturation at $94^{\circ} \mathrm{C}$ for 3 min followed by six 'touch down' cycles of $94^{\circ} \mathrm{C}$ denaturation for $30 \mathrm{~s}$, annealing temperatures $\left(60^{\circ} \mathrm{C}, 58^{\circ} \mathrm{C}, 56^{\circ} \mathrm{C}, 54^{\circ} \mathrm{C}, 52^{\circ} \mathrm{C}, 50^{\circ} \mathrm{C}\right)$ for $30 \mathrm{~s}$ and an extension step of $72^{\circ} \mathrm{C}$ for $45 \mathrm{~s}$. On the completion of the last touchdown cycle, another 35 cycles were carried out at $50^{\circ} \mathrm{C}$ annealing temperature followed by a final extension of $10 \mathrm{~min}$ at $72^{\circ} \mathrm{C}$. PCR products were electrophoresed using a $3130 \times 1$ Genetic Analyzer (Applied Biosystems) and allele sizes were scored using the software Peak Scanner (Applied Biosystems) and checked by eye.

Table 1. Eight microsatellite loci cross-amplified for Pteropus poliocephalus $\mathrm{Ta}=$ annealing temperature

\begin{tabular}{|llllll|}
\hline Locus & Accession \# & Isolated for & Ta $\left({ }^{\circ} \mathrm{C}\right)$ & Repeat & Source \\
\hline A1 & DQ157419 & P. hypomelanus & $60-50$ & GT(27) & O'Brien et al. (2007) \\
A3 & DQ157422 & P. rodricensis & $55-47$ & TG(18) & O'Brien et al. (2007) \\
C6 & DQ157426 & P. rodricensis & $60-50$ & GAT(15) & O'Brien et al. (2007) \\
PH9 & DQ157414 & P. hypomelanus & $60-50$ & AT(4)GT(13)AT(7) & O'Brien et al. (2007) \\
PC25b6 & DQ916124 & P. conspicillatus & $60-50$ & TG(11) & Fox et al. (2007) \\
PC26a7 & DQ916126 & P. conspicillatus & $60-50$ & TG(17) & Fox et al. (2007) \\
PC31h4 & DQ916130 & P. conspicillatus & $60-50$ & TG(9) & Fox et al. (2007) \\
PC36c2 & DQ916127 & P. conspicillatus & $60-50$ & GTCTCTCT(4) & Fox et al. (2007) \\
\hline
\end{tabular}

Preliminary data obtained during loci optimisation for faecal DNA revealed genotyping inconsistencies between replicates and low levels of amplification success. To further investigate the nature and extent of errors and to determine whether consensus genotypes could be obtained, a multitube procedure (Navidi et al. 1992; Taberlet et al. 1996) comprising eight PCR replicates was performed for the locus that appeared to have the strongest amplification (C6). Consensus genotypes were assigned conservatively following Taberlet et al. (1996), with an allele accepted only where observed in at least two independent replicates, and a homozygote accepted only if observed in seven amplifications. For each individual, eight replicate PCR amplifications of hair-derived DNA at locus C6 were carried out for comparison with results of faecal DNA amplifications. In each round of replicate PCRs a wing sample was amplified as a positive control. 
A multiplex nested PCR amplification approach outlined by Piggott et al. (2004) is reported to reduce genotyping error and improve amplification success. We trialled this method for faecal-derived DNA samples using a modified protocol using Taq buffer (Promega; Step 1: $5 \mathrm{x}$, Step 2: $2 \mathrm{x}$ ), with omission of Tween 20 and $\mathrm{NaSO}_{4}$, and with addition of BSA (Promega, final concentration $1 \mathrm{mg}$ per $10 \mu \mathrm{L}$ ) and Q solution (Qiagen, $2 \mu \mathrm{L}$ per $10 \mu \mathrm{L}$ ), with $0.5 \mathrm{U}$ per $10 \mu \mathrm{L}$ Taq polymerase, and forward and reverse primer concentrations of $10 \mu \mathrm{M}$ (Step 1) and $5 \mu \mathrm{M}$ (Step 2).

\section{Calculation of genotyping error rates}

We estimated rates of allelic dropout (ADO) and false alleles (FA) from individuals for which single locus (C6) consensus genotypes were assigned. A substantial proportion of replicates failed to amplify, so the rate of non-amplification was also calculated. An additional error type was calculated, the rate of spurious profiles, for microsatellite traces characterised by spurious peaks or excessive stutter from which genotypes could not be resolved.

The rate of non-amplification was calculated by dividing the number of genotyping runs showing only primer-dimer peaks or non-specific product over the total number of PCRs. The rate of spurious profiles was calculated as the ratio of genotypes that were ambiguous owing to spurious profiles over the total number of amplifications.

The ADO rate was estimated by calculating the ratio of genotypes scored as homozygous over the total number of positive amplifications of individuals with a heterozygous consensus genotype (Broquet and Petit 2004). For one hair sample for which a consensus was not assigned, the ADO rate was calculated based on a genotype confirmed from a tissue sample. A paired $t$-test was conducted using Minitab 15 (Minitab Inc.) to test for short allele dominance in replicates of heterozygous individuals observed with ADO, based on the rate of dropout of the larger or smaller allele assigned by consensus genotype (Wattier et al. 1998). The FA rate was calculated by dividing the number of positive amplifications scoring a different heterozygous genotype to the consensus over the total number of positive amplifications (Broquet and Petit 2004).

Total error rate was estimated as the sum of the ADO rate and the FA rate (Gagneux et al. 1997; Goossens et al. 1998). The total error rate was estimated only for individuals with both alleles assigned and where four or more positive amplifications were observed. Spurious profiles were excluded from the total error rate as they are able to be identified and removed from datasets and are thus unlikely to result in erroneous genotypes being assigned.

\section{Results}

\section{DNA extraction}

DNA was successfully extracted from all wing $(n=4)$ and faecal $(n=20)$ samples and seven of eight hair samples. Extracted DNA visualised on a $2 \%$ agarose gel indicated that higher quality and quantity DNA was obtained from wing samples. PCR amplification of both nuclear and mitochondrial DNA was successful for all DNA sources. Mitochondrial sequence data obtained from faecal-derived DNA were confirmed as Pteropus in origin by sequence matching in GenBank (98\% match to P. poliocephalus; partial mtDNA sequence, $E=0.0$, Accession \#FJ548588.1). Seven of the eight microsatellites were successfully amplified using faecal-derived DNA as a template (Locus PH9 only PCR amplified from DNA extracted from wing tissue). 


\section{Mitochondrial sequencing}

Mitochondrial sequencing resulted in clear, high-quality traces for 17 of 19 individuals (faeces $=15$, hair $=$ 1 , wing =1), from which 14 sequences could be read to 765 base pairs (faeces $=12$, hair $=1$, wing $=1$ ). Two faecal samples were removed owing to apparent contamination. Sequences were trimmed at 635 base pairs and resolved 17 haplotypes (haplotype diversity $=1$ ). An exceptionally high haplotypic diversity at mitochondrial D-loop was also noted by Chan (2007).

\section{Microsatellite genotyping of faecal DNA}

Faecal-derived DNA was successfully amplified in five of the seven loci and resulted in the identification of a genotype in half the individuals used in the multitube approach. PCR success was moderate, with $\sim 60 \%$ of individual samples amplifying.

Of the seven microsatellite loci that amplified from faecal-derived DNA, genotypes could be confidently assigned in five loci ( $\mathrm{A} 1, \mathrm{~A} 3, \mathrm{C} 6, \mathrm{PC} 25 \mathrm{~b} 6, \mathrm{PC} 26 \mathrm{a} 7)$; the remaining two loci were problematic owing to excessive numbers of peaks or poor amplification. Nonetheless, inconsistencies were apparent during replicate runs with these five loci. Our exploration of this problem with the multitube trial (eight replicate runs) conducted for locus C6 allowed consensus genotypes to be assigned for 10 of 20 individuals (Table 2).

The value of the multitube approach is highlighted by the error rates observed across replicate runs. Total ADO rate was estimated at $45.9 \%$ for locus $C 6$, and ranged from 0 to 0.8 for the 20 individuals tested (Table 2). A higher tendency of dropout was observed for longer (mean rate $=0.63 \pm 0.41$ ) than shorter alleles (mean rate $=0.28 \pm 0.37)$, though this difference was not significant $(n=11$, paired $t$-test: $P=$ 0.135). The rate of FA was $3.7 \%$, and total error rate estimated at $49.6 \%$. Only a single individual was assigned a consensus genotype with error-free replicates from faecal DNA.

Multiplex PCR amplification was found to reduce amplification success, with DNA from just one of 20 faecal samples and a wing tissue sample visualised using agarose gel electrophoresis. We therefore decided not to pursue this approach.

\section{Microsatellite genotyping of hair-derived DNA}

The multitube approach was less successful with hair-derived DNA than with faecal-derived DNA. Of eight hair-derived DNA amplifications, two could be assigned consensus genotypes (Table 3). A further two individuals were assigned a single allele, with the other allele remaining uncertain. Overall, $34 \%$ of reactions amplified (Table 3). From this limited sample size the ADO was observed in one individual, no false alleles were observed and therefore the total error rate was $12.5 \%$.

\section{Discussion}

Conservation management has benefitted greatly from the development of genetic approaches to assess population partitioning, dispersal events and extinction risk in species of concern (e.g. Spielman et al. 2004). However, direct tissue sampling is often challenging and unnecessarily stressful for the animals. We have demonstrated that DNA remotely sampled from grey-headed flying-fox faeces may be utilised to assay both mitochondrial and nuclear DNA by PCR.

Our results suggest that both faeces and hair of $P$. poliocephalus provide a source of high-quality mitochondrial DNA. The exceptionally high haplotypic diversity observed here is comparable to that reported by Chan (2007), with 65 haplotypes resolved from 88 individuals (haplotype diversity $=0.74$ ). 
Our findings are consistent with reports that remotely sampled mitochondrial DNA is not subject to the reduced quality or accuracy that may affect microsatellites (Morin et al. 1994; Taberlet et al. 1999).

Table 2. Genotyping of locus C6 from faecal DNA

\# reps = number of replicates. \# pos. amp. = number of positive amplifications. \# obs. GT= number of observed genotypes. Rate $A D O=$ rate of allelic dropout observed. RateFA = rate of false alleles observed. Est.GT error rate $=$ estimated genotyping error rate.Wing1 = wing-tissue-derived DNA (positive control). Totals refer to total counts and rates for locus C6 calculated for faecal samples only (see Methods)

\begin{tabular}{|ccccccccc|}
\hline Individual & \# reps & $\begin{array}{c}\text { \# pos. } \\
\text { amp. }\end{array}$ & \#obs. GT & $\begin{array}{c}\text { Consensus GT } \\
\text { assigned }\end{array}$ & $\begin{array}{c}\text { Rate } \\
\text { ADO }\end{array}$ & Rate FA & $\begin{array}{c}\text { Spurious } \\
\text { Profile }\end{array}$ & $\begin{array}{c}\text { Est. GT } \\
\text { error rate }\end{array}$ \\
\hline F1 & 11 & 11 & 3 & $262 / 268$ & 0.36 & 0.18 & 0.09 & 0.55 \\
F2 & 11 & 8 & 2 & $262 / 280$ & 0.63 & 0.00. & 0.00 & 0.63 \\
F3 & 11 & 5 & 2 & $262 / 280$ & 0.60 & 0.00 & 0.00 & 0.60 \\
F4 & 11 & 5 & 2 & $262 / 280$ & 0.40 & 0.00 & 0.09 & 0.40 \\
F5 & 11 & 8 & 2 & $262 / 280$ & 0.75 & 0.00 & 0.00 & 0.75 \\
F6 & 11 & 6 & 4 & $262 / 280$ & 0.67 & 0.17 & 0.00 & 0.83 \\
F7 & 11 & 7 & 3 & $262 / 280$ & 0.71 & 0.00 & 0.00 & 0.71 \\
F8 & 11 & 10 & 4 & $262 / 268$ & 0.40 & 0.10 & 0.10 & 0.50 \\
F9 & 11 & 10 & 1 & $262 / 286$ & 0.00 & 0.00 & 0.00 & 0.00 \\
F10 & 11 & 5 & 3 & $262 / 280$ & 0.80 & 0.00 & 0.00 & 0.80 \\
F11 & 11 & 10 & 3 & $262 / 280$ & 0.20 & 0.10 & 0.00 & 0.30 \\
F12 & 11 & 8 & 4 & $262 / ?$ & -- & -- & 0.00 & - \\
F13 & 6 & 6 & 1 & $262 / ?$ & -- & -- & 0.00 & - \\
F14 & 11 & 4 & 1 & $262 / ?$ & -- & -- & 0.00 & - \\
F15 & 11 & 6 & 5 & $262 / ?$ & -- & -- & 0.09 & - \\
F16 & 11 & 11 & 3 & $283 / ?$ & -- & -- & 0.00 & -- \\
F17 & 8 & 5 & 1 & $262 / ?$ & -- & -- & 0.13 & -- \\
F18 & 12 & 1 & 1 & None & -- & -- & 0.00 & -- \\
F19 & 8 & 7 & 2 & None & -- & -- & 0.63 & -- \\
F20 & 11 & 2 & 2 & None & -- & -- & 0.00 & -- \\
Wing 1 & 11 & 11 & 1 & $262 / 280$ & 0.00 & 0.00 & 0.00 & 0.00 \\
Total & 210 & 135 & 13 & 11 & 0.459 & 0.037 & 0.048 & 0.496 \\
\hline
\end{tabular}

Extracted nuclear DNA was found to be of lower quality and affected by reduced amplification success, allelic dropout, false alleles and spurious microsatellite profiles. Here we applied two approaches outlined in the current literature to address these issues. Despite success in previous studies (Bellemain and Taberlet 2004; Piggott et al. 2004), the multiplex pre-amplification method dramatically decreased amplification success for faecal DNA. Conversely, the trialled multitube approach (Navidi et al. 1992; Taberlet et al. 1996) had greater success and allowed genotypes to be assigned. Overall, faecal DNA provided a higher proportion of successful amplifications and identified genotypes (57\%) when compared with hair samples (34\%). Although both success rates reported here are relatively low, they are comparable to those observed in previous studies (30\%: Bayes et al. 2000; 47\%: Smith et al. 2000) using baboon faecal material. A nonsignificant trend towards greater dropout rates for larger alleles provides some evidence for short allele dropout (Wattier et al. 1998). 
Table 3. Genotyping of locus $\mathbf{C} 6$ from hair-derived DNA

\# reps = number of replicates. $\#$ pos. amp. = number of positive amplifications. \# obs. GT= number of observed genotypes. Rate $A D O=$ rate of allelic dropout observed. Rate $F A=$ rate of false alleles observed. Est. GT error rate $=$ estimated genotyping error rate

\begin{tabular}{|c|c|c|c|c|c|c|c|c|}
\hline Individual & \# reps & $\begin{array}{l}\text { \# pos. } \\
\text { amp. }\end{array}$ & \#obs. GT & $\begin{array}{l}\text { Consensus GT } \\
\text { assigned }\end{array}$ & $\begin{array}{l}\text { Rate } \\
\text { ADO }\end{array}$ & Rate FA & $\begin{array}{c}\text { Spurious } \\
\text { Profile }\end{array}$ & $\begin{array}{l}\text { Est. GT } \\
\text { error rate }\end{array}$ \\
\hline $\mathrm{H} 1^{\mathrm{A}}$ & 8 & 8 & 1 & $262 / 262$ & -- & 0 & 0 & 0 \\
\hline $\mathrm{H} 2$ & 7 & 7 & 1 & $262 / 280$ & 0 & 0 & 0 & 0 \\
\hline $\mathrm{H} 3$ & 8 & 4 & 3 & $262 / ?$ & -- & -- & 0 & -- \\
\hline $\mathrm{H} 4$ & 7 & 5 & 1 & 262/? & -- & -- & 0.43 & -- \\
\hline $\mathrm{H} 5$ & 8 & 4 & 1 & None & -- & -- & 0.38 & -- \\
\hline $\mathrm{H} 6$ & 8 & 2 & 1 & None & -- & -- & 0.13 & -- \\
\hline $\mathrm{H} 7$ & 7 & 0 & 0 & None & -- & -- & -- & -- \\
\hline $\mathrm{H} 8$ & 8 & 1 & 1 & None & $1^{B}$ & 0 & 0 & -- \\
\hline Wing $2^{C}$ & 8 & 8 & 1 & $262 / 289$ & 0 & 0 & 0 & 0 \\
\hline Total & 69 & 39 & 6 & 2 & 0.125 & 0 & 0.087 & 0.125 \\
\hline
\end{tabular}

${ }^{\mathrm{A}}$ DNA extracted from plucked hair

${ }^{B}$ Based on a single amplification and comparison with Wing2

${ }^{\mathrm{C}}$ Wing2 $=$ wing-tissue-derived DNA from individual $\mathrm{H} 8$

Although amplification and genotyping success was greater from faecal samples, they suffered greater rates of genotyping errors. Small sample sizes for ADO and FA tests owing to this lower rate of amplification success and consensus genotype assignment may account for this result. Incidences of allelic dropout and false alleles in faecal material ( $A D O=44.7 \%, F A=2.6 \%$ ) were much higher than those observed in hair-derived samples ( $A D O=12.5 \%, F A=0$ ). Genotyping reliability is a common problem in non-invasive faecal sampling (Taberlet et al. 1999; Broquet and Petit 2004; Piggott et al. 2004;Pompanonet al. 2005), perhaps a result of poor-quality DNA or PCR inhibitors (Taberlet et al. 1996; Maudet et al. 2004).

Conducting a pilot study such as this is highly recommended before investing time and money into a research project using non-invasive sampling (Taberlet et al. 1999; Banks et al. 2002; Broquet et al. 2007). The multitube approach can be both expensive and time-consuming, and requires large volumes of DNA that may not be available for studies involving multiple loci (Taberlet et al. 1997). By estimating genotyping error rates and amplification failure, the most appropriate DNA source, number of replicates required, cost and feasibility of a study can be assessed (Taberlet et al. 1999; Banks et al. 2002; Miller et al. 2002). Our findings suggest that a multitube approach consisting of eight replicates is required for reliable microsatellite genotyping of grey-headed flying-fox faecal material, and that shed hair is a less efficient and cost-effective source of nuclear DNA for this species.

\section{Acknowledgements}

We thank the Ku-ring-gai Bat Conservation Society Inc. (KBCS), in particular Marjorie Beck and Tim Pearson, for their assistance with sampling, the Macquarie University Sequencing Facility for their assistance with genotyping and sequencing, Anja Divljan (University of Sydney) for donating wing puncture samples and Macquarie University for funding the project. 


\section{References}

Banks, S., Piggott, M., Hansen, B., Robinson, N., and Taylor, A. (2002). Wombat coprogenetics: enumerating a common wombat population by microsatellite analysis of faecal DNA. Australian Journal of Zoology 50, 193-204. doi:10.1071/ZO01072

Bayes, M., Smith, K., Alberts, S., Altmann, J., and Bruford, M. (2000). Testing the reliability of microsatellite typing from faecal DNA in the savannah baboon. Conservation Genetics 1, 173176. doi:10.1023/A:1026595324974

Bellemain, E., and Taberlet, P. (2004). Improved noninvasive genotyping method: application to brown bear (Ursus arctos) faeces. Molecular Ecology Notes 4, 519-522. doi:10.1111/j.14718286.2004.00711.x

Broquet, T., and Petit, E. (2004). Quantifying genotyping errors in noninvasive population genetics. Molecular Ecology 13, 3601-3608. doi:10.1111/j.1365-294X.2004.02352.x

Broquet, T., Ménard, N., and Petit, E. (2007). Noninvasive population genetics: a review of sample source, diet, fragment length and microsatellite motif effects on amplification success and genotyping error rates. Conservation Genetics 8, 249-260. doi:10.1007/s10592-006-9146-5

Chan, J. (2007). Genetic estimates of dispersal and the implications for conservation management of the grey-headed flying-fox (Pteropus poliocephalus). B.Sc.(Honours) Thesis, University of New South Wales, Sydney.

Eby, P. (1991). Seasonal movements of grey-headed flying-foxes, Pteropus poliocephalus (Chiroptera: Pteropodidae), from two maternity camps in northern New South Wales. Wildlife Research 18, 547-559. doi:10.1071/WR9910547

Eby, P., and Lunney, D. (2002). Managing the grey-headed flying-fox Pteropus poliocephalus as a threatened species: a context for the debate. In 'Managing the Grey-headed Flying-fox as a Threatened Species in NSW'. (Eds P. Eby and D. Lunney.) pp. 1-15. (Royal Zoological Society of New South Wales: Sydney.)

Eby, P., Richards, G., Collins, L., and Parry-Jones, K. (1999). The distribution, abundance and vulnerability to population reduction of a nomadic nectarivore, the grey-headed flying-fox (Pteropus poliocephalus) in New South Wales, during a period of resource concentration. Australian Zoologist 31, 240-255.

Ernest, H., Penedo, M., May, B., Syvanen, M., and Boyce, W. (2000). Molecular tracking of mountain lions in the Yosemite Valley region in California: genetic analysis using microsatellites and faecal DNA. Molecular Ecology 9, 433-441. doi:10.1046/j.1365-294x.2000.00890.x

Fox, S., Waycott, M., and Dunshea, G. (2007). Isolation and characterization of polymorphic microsatellite loci in the vulnerable spectacled flying fox, Pteropus conspicillatus. Conservation Genetics 8, 1013-1016. doi:10.1007/s10592-006-9223-9

Frantzen, M. A. J., Silk, J. B., Ferguson, J. W. H., Wayne, R. K., and Kohn, M. H. (1998). Empirical evaluation of preservation methods for faecal DNA. Molecular Ecology 7, 1423-1428. doi:10.1046/j.1365-294x.1998.00449.x

Fujita, M., and Tuttle, M. (1991). Flying foxes (Chiroptera: Pteropodidae): threatened animals of key ecological and economic importance. Conservation Biology 5, 455-463. doi:10.1111/j.15231739.1991.tb00352.x

Gagneux, P., Boesch, C., and Woodruff, D. (1997). Microsatellite scoring errors associated with noninvasive genotyping based on nuclear DNA amplified from shed hair. Molecular Ecology 6, 861-868. doi:10.1111/j.1365-294X.1997.tb00140.x

Gerloff, U., Schlötterer, C., Rassmann, K., Rambold, I., Hohmann, G., Fruth, B., and Tautz, D. (1995). Amplification of hypervariable simple sequence repeats (microsatellites) from excremental DNA of wild living bonobos (Pan paniscus). Molecular Ecology 4, 515-518. doi:10.1111/j.1365294X.1995.tb00247.x 
Goossens, B., Waits, L., and Taberlet, P. (1998). Plucked hair samples as a source of DNA: reliability of dinucleotide microsatellite genotyping. Molecular Ecology 7, 1237-1241. doi:10.1046/j.1365294x.1998.00407.x

Hall, L. S., and Richards, G. (2000). 'Flying Foxes: Fruit and Blossom Bats of Australia.' (University of New South Wales Press: Sydney.)

Maudet, C., Luikart, G., Dubray, D., Von Hardenberg, A., and Taberlet, P. (2004). Low genotyping error rates in wild ungulate faeces sampled in winter. Molecular Ecology Notes 4, 772-775. doi:10.1111/j.1471-8286.2004.00787.x

Miller, C., Joyce, P., and Waits, L. (2002). Assessing allelic dropout and genotype reliability using maximum likelihood. Genetics 160, 357-366.

Morin, P., Moore, J., Chakraborty, R., Jin, L., Goodall, J., and Woodruff, D. (1994). Kin selection, social structure, gene flow, and the evolution of chimpanzees. Science 265, 1193-1201. doi:10.1126/science. 7915048

Navidi, W., Arnheim, N., and Waterman, M. (1992). A multiple-tubes approach for accurate genotyping of very small DNA samples by using PCR: statistical considerations. American Journal of Human Genetics 50, 347-359.

O'Brien, J., McCracken, G., Say, L., and Hayden, T. (2007). Rodrigues fruit bats (Pteropus rodricensis, Megachiroptera: Pteropodidae) retain genetic diversity despite population declines and founder events. Conservation Genetics 8, 1073-1082. doi:10.1007/s10592-006-9263-1

Olival, K. (2008). Population genetic structure and phylogeography of Southeast Asian flying foxes: implications for conservation and disease ecology. Ph.D. Thesis, Columbia University, New York.

Palmer, C., and Woinarski, J. (1999). Seasonal roosts and foraging movements of the black flying fox (Pteropus alecto) in the Northern Territory: resource tracking in a landscape mosaic. Wildlife Research 26, 823-838. doi:10.1071/WR97106

Piggott, M., Bellemain, E., Taberlet, P., and Taylor, A. (2004). A multiplex pre-amplification method that significantly improves microsatellite amplification and error rates for faecal DNA in limiting conditions. Conservation Genetics 5, 417-420. doi:10.1023/B:COGE.0000031138.67958.44

Pompanon, F., Bonin, A., Bellemain, E., and Taberlet, P. (2005). Genotyping errors: causes, consequences and solutions. Nature Reviews Genetics 6, 847-859. doi:10.1038/nrg1707

Puddicombe, R. (1981). A behavioural study of the grey-headed flying fox (Pteropus poliocephalus). B.Sc.(Honours) Thesis, University of New England, Armidale.

Regnaut, S., Lucas, F., and Fumagalli, L. (2006). DNA degradation in avian faecal samples and feasibility of non-invasive genetic studies of threatened capercaillie populations. Conservation Genetics 7, 449-453. doi:10.1007/s10592-005-9023-7

Segelbacher, G., and Steinbruck, G. (2001). Bird faeces for sex identification and microsatellite analysis. Vogelwarte 41, 139-142.

Sloane, M., Sunnucks, P., Alpers, D., Beheregaray, L., and Taylor, A. (2000). Highly reliable genetic identification of individual northern hairy-nosed wombats from single remotely collected hairs: a feasible censusing method. Molecular Ecology 9, 1233-1240. doi:10.1046/j.1365294x.2000.00993.x

Smith, K., Alberts, S., Bayes, M., Bruford, M., Altmann, J., and Ober, C. (2000). Cross-species amplification, non-invasive genotyping, and non-Mendelian inheritance of human STRPs in savannah baboons. American Journal of Primatology 51, 219-227. doi:10.1002/10982345(200008) 51:4<219::AID-AJP1>3.0.CO;2-G

Spielman, D., Brook, B., and Frankham, R. (2004). Most species are not driven to extinction before genetic factors impact them. Proceedings of the National Academy of Sciences of the United States of America 101, 15261-15264. doi:10.1073/pnas.0403809101 
Sunnucks, P., and Hales, D. F. (1996). Numerous transposed sequences of mitochondrial cytochrome oxidase I-II in aphids of the genus Sitobion (Hemiptera: Aphididae). Molecular Biology and Evolution 13, 510-524.

Taberlet, P., Griffin, S., Goossens, B., Questiau, S., Manceau, V., Escaravage, N., Waits, L., and Bouvet, J. (1996). Reliable genotyping of samples with very low DNA quantities using PCR. Nucleic Acids Research 24, 3189-3194. doi:10.1093/nar/24.16.3189

Taberlet, P., Camarra, J., Griffin, S., Uhres, E., Hanotte, O., Waits, L., Dubois-Paganon, C., Burke, T., and Bouvet, J. (1997). Noninvasive genetic tracking of the endangered Pyrenean brown bear population. Molecular Ecology 6, 869-876. doi:10.1111/j.1365-294X.1997.tb00141.x

Taberlet, P., Waits, L., and Luikart, G. (1999). Noninvasive genetic sampling: look before you leap. Trends in Ecology \& Evolution 14, 323-327.

Wattier, R., Engel, C., Saumitou-Laprade, P., and Valero, M. (1998). Short allele dominance as a source of heterozygote deficiency at microsatellite loci: experimental evidence at the dinucleotide locusGv1CTin Gracilaria gracilis (Rhodophyta). Molecular Ecology 7, 1569-1573. doi:10.1046/j.1365-294x.1998.00477.x 